\title{
SPEED AND TORQUE CONTROL OF AN INDUCTION MOTOR WiTH ANN BASED DTC
}

\author{
Fatih Korkmaz \\ Department of Electric-Electronic Engineering, Çankırı Karatekin University, \\ Uluyazı Kampüsü, Çankırı, Turkey
}

\begin{abstract}
Due to advantages such as fast dynamic response, simple and robust control structure, direct torque control (DTC) is commonly used method in high performance control method for induction motors. Despite mentioned advantages, there are some chronically disadvantages with this method like high torque and current ripples, variable switching behaviour and control problems at low speed rates. On the other hand, artificial neural network (ANN) based control algorithms are getting increasingly popular in recent years due to their positive contribution to the system performance. The purpose of this paper is investigating of the effects of ANN integrated DTC method on induction motor performance by numerical simulations. For this purpose, two different ANN models have been designed, trained and implemented for the same DTC model. The first ANN model was designed to select optimum inverter and the second model was designed to use in the determination of the flux vector position. Matlab/Simulink model of the proposed ANN based DTC method was created in order to compare with the conventional DTC and the proposed DTC methods. The simulation studies proved that the induction motor torque ripples have been reduced remarkably with the proposed method and this approach can be a good alternative to the conventional DTC method for induction motorcontrol.
\end{abstract}

\section{KEYWORDS}

Direct torque control, induction motor control, Artificial neural networks

\section{INTRODUCTION}

There is no doubt about the importance of the induction motors for industrial environments and applications. Induction motors are most widely used motor type due to its unique structure and advantages. In the past, induction motors were dominant for the constant speed motor applications while DC motors were used for applications which require variable speed. But, all rules had changed in the beginning of the 1970's with the proposing of the vector control, in parallel to development in power electronic devices and computer world. Today, conventional DC motors are almost replaced with induction motors including variable speed systems.

Vector based control method was proposed by Blascke in 1970's and it was named as field oriented control (FOC). About ten year later, another vector based control method had been presented by Takahashi and it was named as DTC. The FOC and the DTC methods have been used in industrial motor driver systems for many years[1-2].

When compared with the FOC, the DTC method has some structural advantages such as simple control algorithm, robust controller character due to independency of motor parameters, needs only stator phase resistance, and fast dynamic response. However, the DTC method has some handicaps that can be listed as, high torque and current ripples, variable switching frequency behavior, and implementation limitations owing to necessity of low sampling time [3].

DOI : $10.5121 /$ ijics.2017.7102 
mOver the last decades, many kind of DTC algorithms have been proposed by researchers to overcome mentioned handicaps and most of them have focused on motor ripples side. In [4], researchers proposed matrix converter based model predictive control approach and they proved that it can be effective in minimizing torque ripples. In [5], authors presents a modified DTC algorithm for permanent magnet synchronous motor drives with fast torque dynamics and constant switching frequency. The authors presents the DTC method using fuzzy controller to minimize torque ripples for BLDC in [6] and for induction motors in [7]. Artificial neural network model based DTC systems have also been investigated to reduce torque ripples in [8].

This paper presents a new multi ANNs model to reduce torque ripples on DTC controlled induction motor drives. Two different ANN models have been designed, trained and implemented. The first ANN model has been used for switch selecting process and the second one has been used for sector determine process. Matlab/Simulink model of the proposed ANN based DTC method was created in order to compare with the conventional DTC and the proposed DTC methods.

\section{Direct TORQue CONTROL}

Direct torque control (DTC) is the name of reliable and energy efficiency vector control method. Despite the DTC was originally proposed for asynchronous motors, over the past years, it has been applied for various motor type such as linear motor, reluctance motor and also PM motors[9].

The mathematic model of the DTC system is based on Clarke transformation. All measured three phase parameters of the motor are converted to two phase components. Instant values of the stator flux and produced motor torque can be calculated with these components as defined with following equations. The Clarke transformation matrix can be written as:

$$
\left[\begin{array}{l}
f_{\alpha} \\
f_{\beta}
\end{array}\right]=\frac{2}{3}\left[\begin{array}{rrr}
1 & -\frac{1}{2} & -\frac{1}{2} \\
0 & \frac{\sqrt{3}}{2} & -\frac{\sqrt{3}}{2}
\end{array}\right]\left[\begin{array}{l}
f_{a} \\
f_{b} \\
f_{c}
\end{array}\right]
$$

Where, $f_{\alpha}, f_{\beta}$ are $\alpha-\beta$ components of motor parameters, and $f_{a}, f_{b}, f_{c}$ are the abc frame components[10-11]. Topology of three phase voltage source inverter that used in the DTC drives is given in Figure 1.

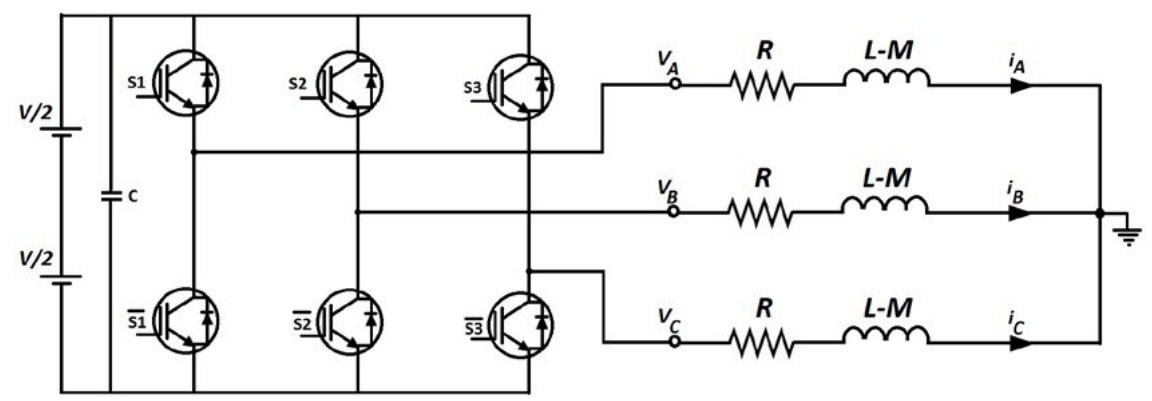

Figure 1. Topology of three phase voltage source inverter

As shown in Figure 1, there are two power switch for each legs of the inverter and only one switch can be conduct mode (denoted by "1") while the other switch is insulation mode (denoted by "0") at any time of drive process to avoid short circuit. For the three phase conduction mode 
International Journal Of Instrumentation And Control Systems (IJICS) Vol.7, No.1, January 2017

working drive systems, the switching states of the VSI can be defined according to three upper switches states as $\mathrm{Si}(\mathrm{i}=1,2,3)$.

$\alpha-\beta$ components of the stator voltages and flux is expressed in following equations.

$$
\begin{aligned}
& v_{s \alpha}=R_{s} i_{s \alpha}+L_{s} \frac{d i_{s \alpha}}{d t} \\
& v_{s \beta}=R_{s} i_{s \beta}+L_{s} \frac{d i_{s \beta}}{d t} \\
& \lambda_{s \alpha}=\int\left(v_{s \alpha}-R_{s} i_{s \alpha}\right) d t \\
& \lambda_{s \beta}=\int\left(v_{s \beta}-R_{s} i_{s \beta}\right) d t
\end{aligned}
$$

The magnitude of the flux can be calculated with;

$$
\lambda=\sqrt{\lambda_{s \alpha}^{2}+\lambda_{s \beta}^{2}}
$$

and position of the stator flux vector is calculated with;

$$
\theta=\arctan \frac{\lambda_{s \beta}}{\lambda_{s \alpha}}
$$

And finally produced motor torque equation can be written as:

$$
T_{e}=\frac{3}{2} p\left(\lambda_{\alpha} i_{\beta}-\lambda_{\beta} i_{\alpha}\right)
$$

In the DTC, motor torque and flux magnitudes directly controlled with control of stator flux vector. The DTC control algorithm is bases on selecting of the appropriate inverter switching state to directly control stator flux vector's speed and length that explain why the method is named as DTC. Hysteresis comparators, that used to keep the torque and flux errors within the defined limits, produce basic control signals.[12].

The schematic diagram of the conventional DTC with mathematical equations is shown in Figure 2. 
International Journal Of Instrumentation And Control Systems (IJICS) Vol.7, No.1, January 2017

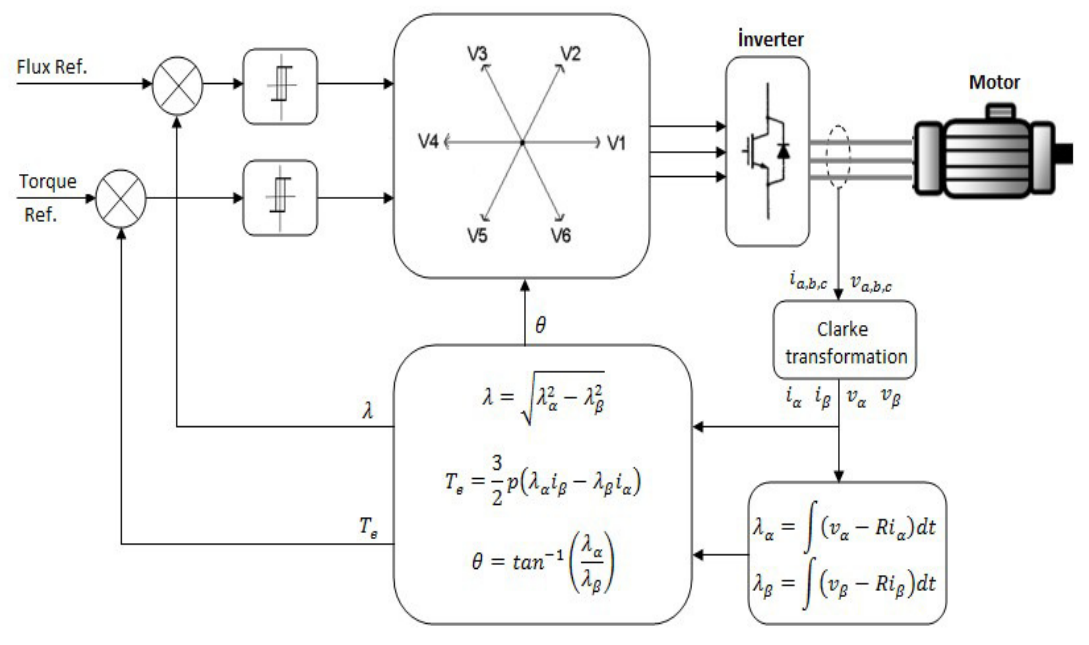

Figure 2. The schematic diagram of the conventional DTC with mathematical equations

\section{PROPOSED DTC SYSTEM}

An ANN model contains interconnected points, which imitates learning way of the biological neurons in human brain, thus, it can model a system similar to human learning. ANN models have rising popularity in different kind of control systems due to their learning abilities, robust structures, beside their modeling success on non-linear and complex mathematical models.

In the proposed ANN based DTC model, two separate ANN models have designed to solve complex processes in conventional DTC approach; selecting appropriate inverter switching states and determining stator flux vector region.

For the first ANN model, $\alpha-\beta$ components of stator flux have used as inputs to determining stator flux vector region process. The ANN model structure is shown in Figure 3.

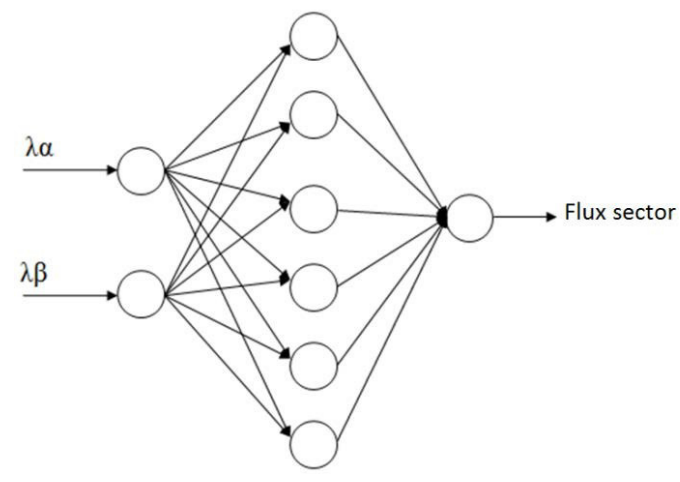

Figure 3. Structure of ANN model for determining stator flux sector 
As shown in Figure 3, flux sector ANN model has two neurons in input layer, six neurons in hidden layer and one neuron in output layer. The ANN was trained about 100000 input data set. 70000 input data were used to train the network while 15000 input data were used for validation and 15000 input data were used for test processes after training. Simulink model of the flux sector ANN and graphical training results are given in Figure 4 and Figure 5, respectively.

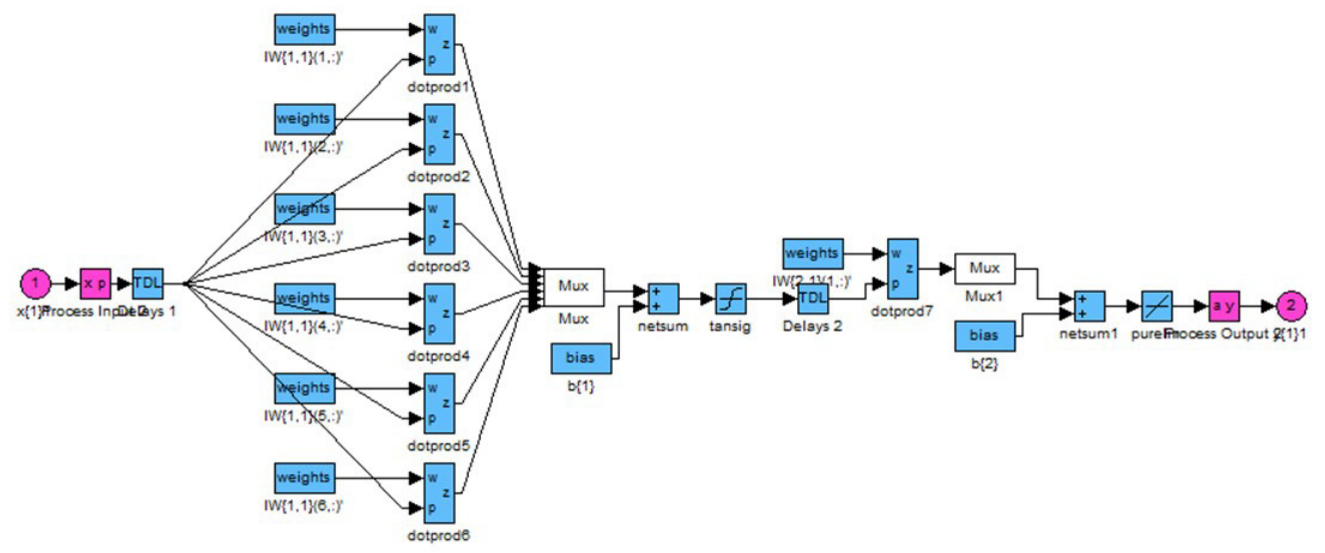

Figure 4. Simulink model of the flux sector ANN

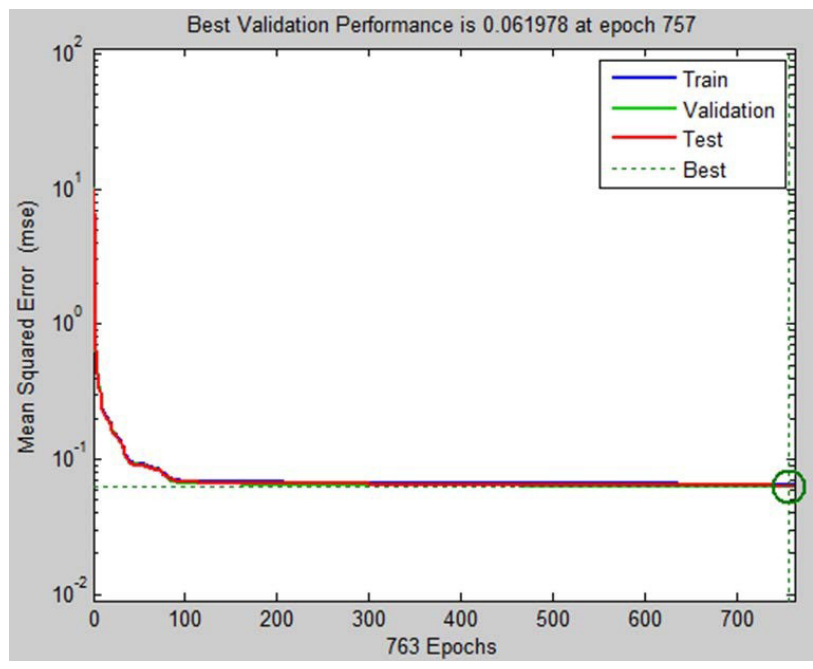

Figure 5. Graphical training results of the first ANN

Outputs of the flux hysteresis, torque hysteresis and flux region data were used as inputs of the second ANN model which was created to determine optimum inverter switching states. Schematic view of the inverter state ANN are given in Figure 6. 


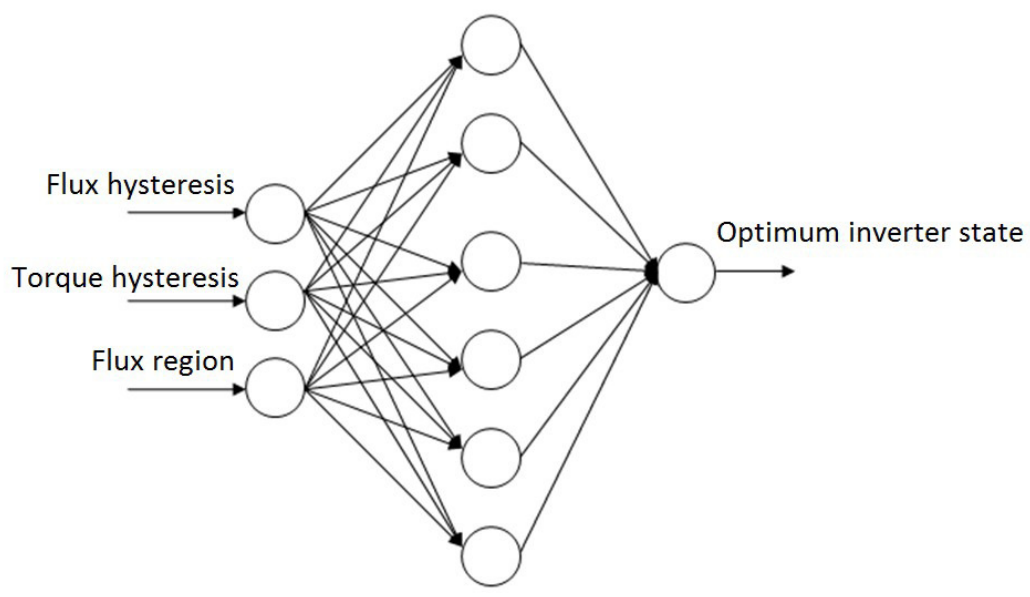

Figure 6. Schematic view of the inverter state ANN

As shown in Figure 6., inverter state ANN model has three neurons in input layer, six neurons in hidden layer and one neuron in output layer. The flux sector ANN was trained about 50000 input data which were obtained with conventional DTC model. 35000 input data were used to train the network while 7500 input data were used for validation and 7500 input data were used for test processes after training. Graphical training results are given in Figure 7.

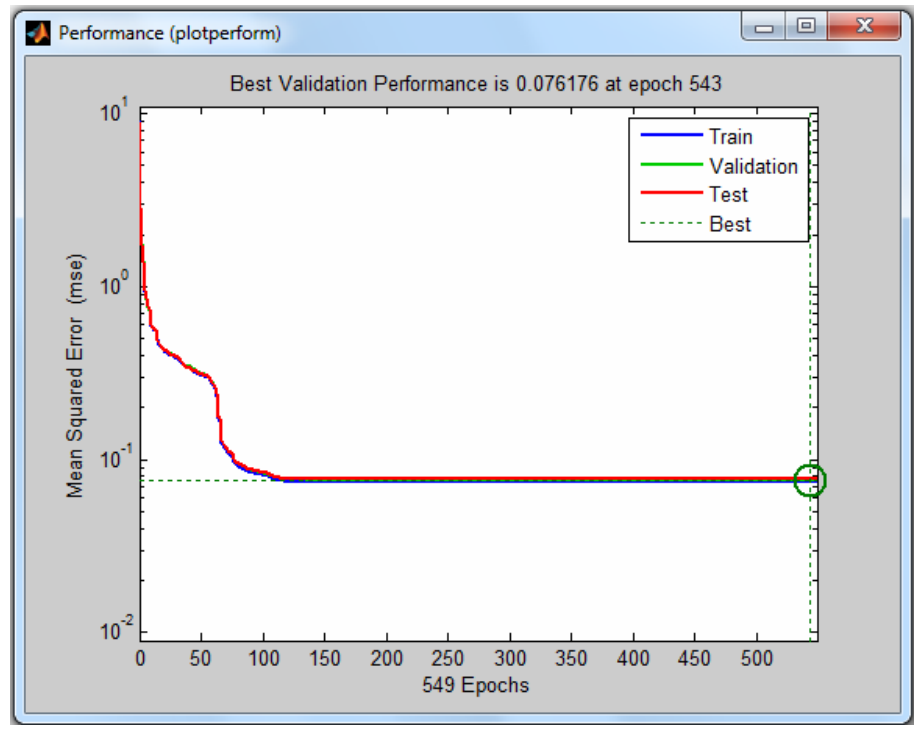

Figure 7. Graphical training results of the second ANN 
Overall Simulink block diagram of the proposed ANN based DTC system is shown in Figure 8.

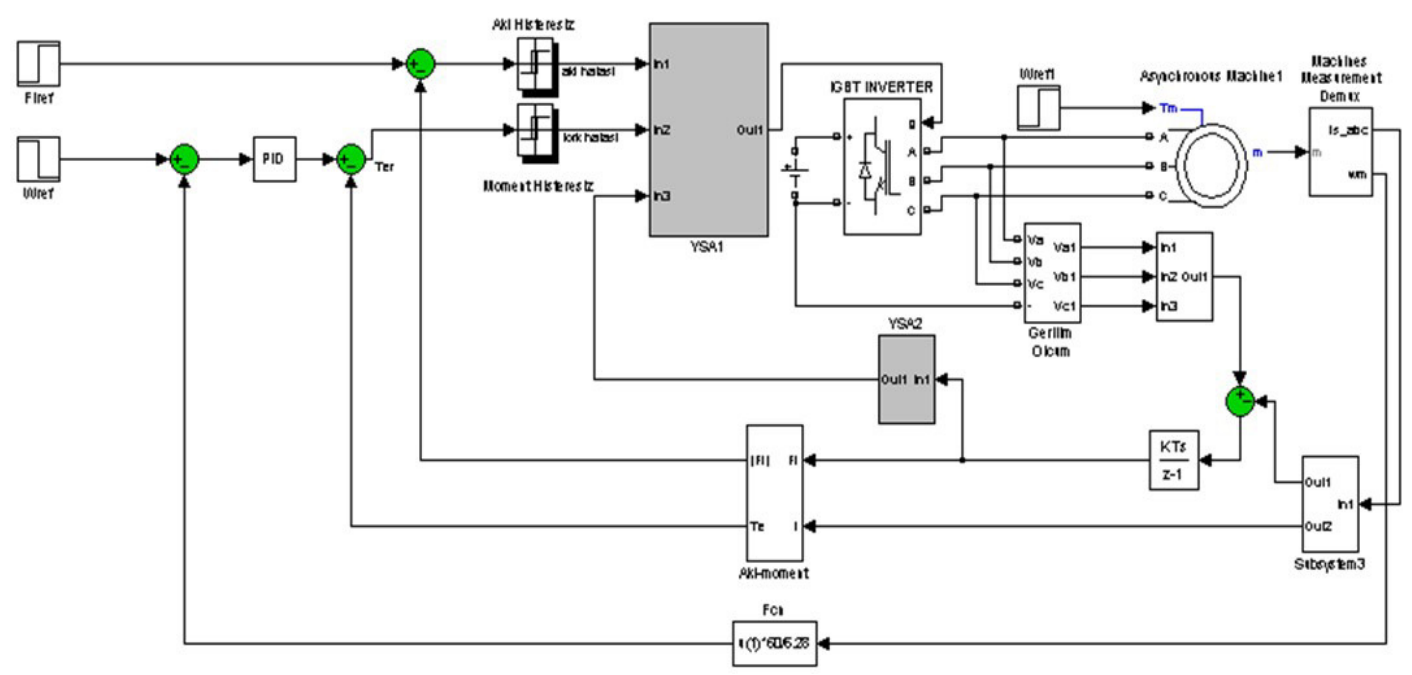

Figure 8. Simulink model of the proposed ANN based DTC system

\section{Simulations}

To provide fair comparison between conventional DTC (C-DTC) and proposed ANN based DTC (ANN-DTC) models, both systems modelled with same control parameters in Matlab/Simulink and three different scenarios were applied and investigated. Asynchronous motor and simulation parameters were presented in Appendix section. Total simulation time was $5 \mathrm{sec}$. and motor load was $0 \mathrm{Nm}$ at the first $3 \mathrm{sec}$. than switched to $3 \mathrm{Nm}$ reference torque after 3 . sec.

In the first scenario, motor was tested at low speed $(250 \mathrm{rpm})$ condition with no-load and loaded conditions. The motor speed and torque responses are given in Figure 9. and Figure 10., respectively.
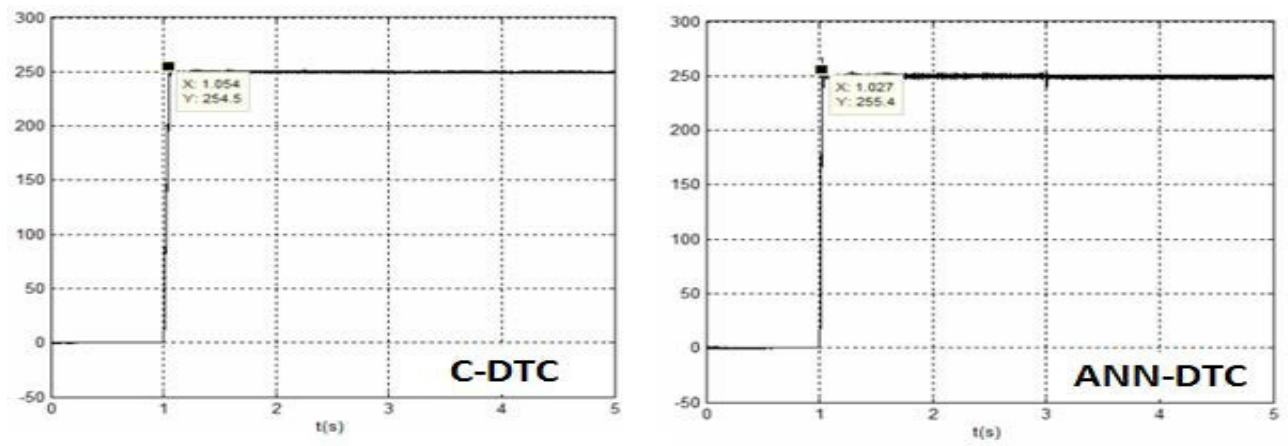

Figure 9. Motor speed responses at $250 \mathrm{rpm}$ speed reference 

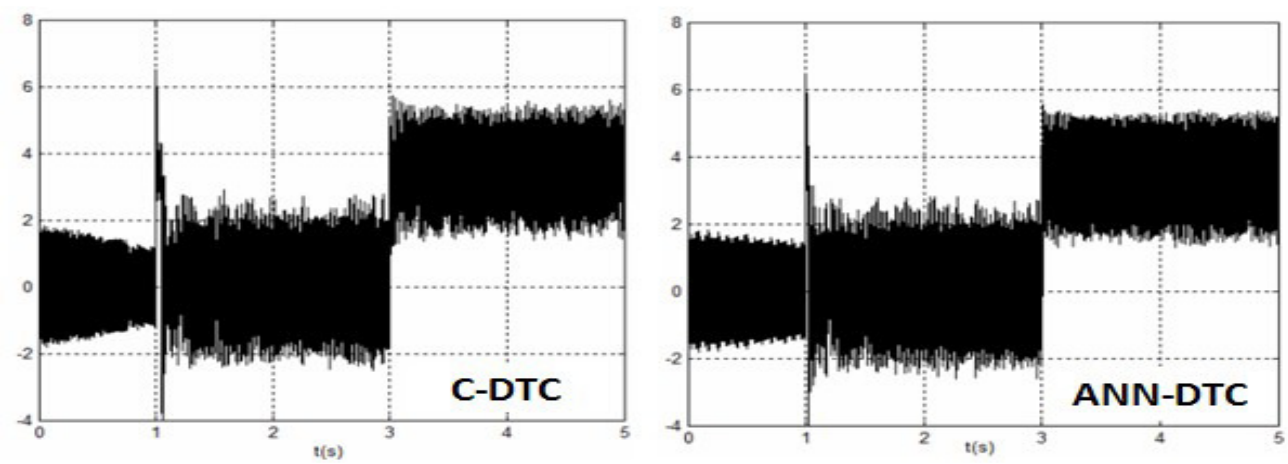

Figure 10. Motor torque responses at $250 \mathrm{rpm}$ speed reference

As shown in Figure 9. and Figure 10., motor speed and torque performances are almost same in low speed working conditions. In both control approach, torque ripples are about $\pm 2 \mathrm{Nm}$ for unloaded period while torque ripples are about $+5 / 1,7 \mathrm{Nm}$ for loaded conditions. Briefly, it can be said that there are no meaning difference between the both methods for low speed conditions.

In the second scenario, motor was tested at half-rated speed (1500 rpm) with no-load and loaded $(3 \mathrm{Nm})$ conditions. The motor speed and torque responses are given in Figure 11. and Figure 12., respectively.
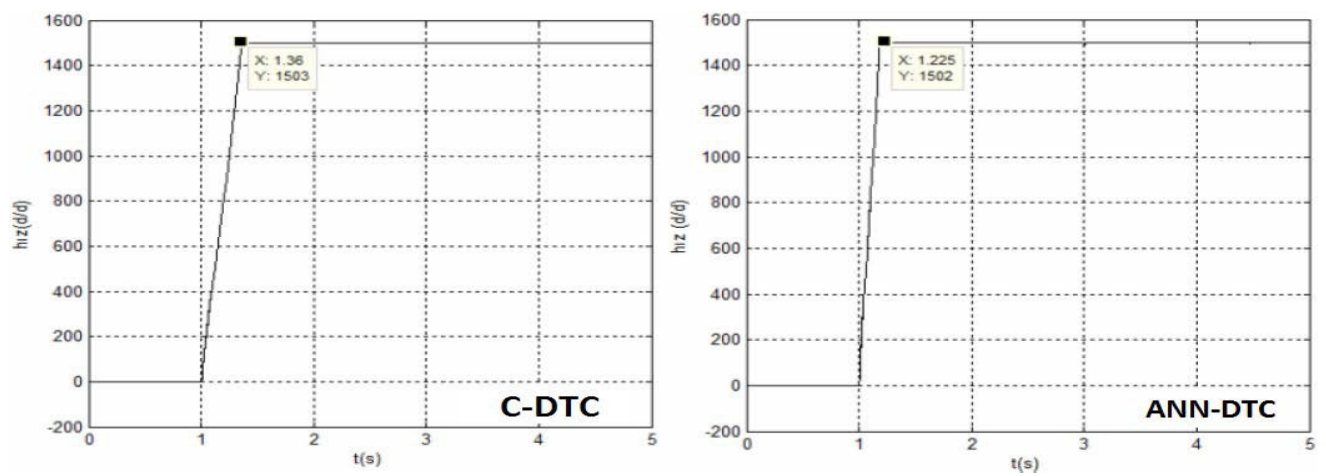

Figure 11. Motor speed responses at $1500 \mathrm{rpm}$ speed reference
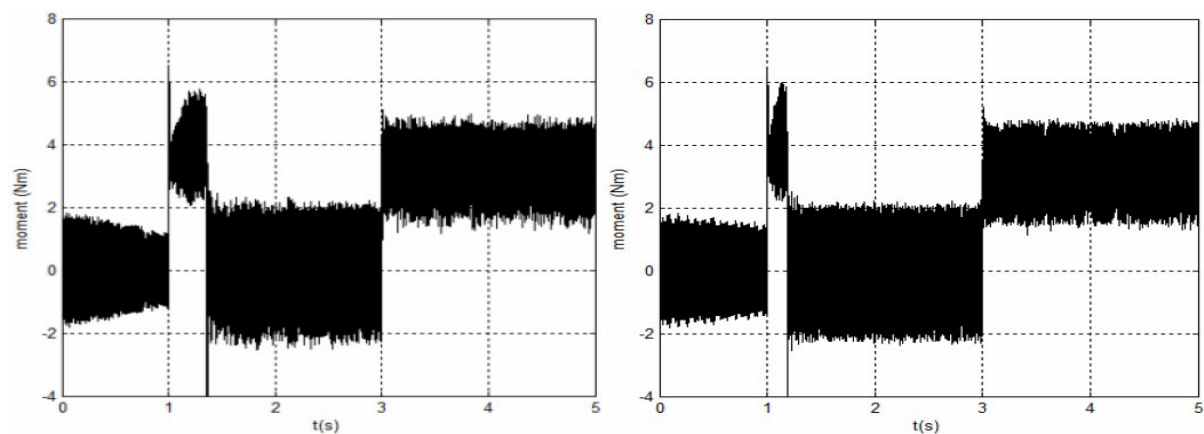

Figure 12. Motor torque responses at $1500 \mathrm{rpm}$ speed reference 
As shown in Figure 11. and Figure 12., motor speed and torque performances are very similar in half-rate speed conditions. In both control approach, torque ripples are about $\pm 2 \mathrm{Nm}$ for unloaded period while torque ripples are about $+5 / 1,7 \mathrm{Nm}$ for loaded conditions. Briefly, it can be said that there are no meaning difference between the both methods for half-rate speed conditions.

In the last scenario, motor was tested at rated speed $(2800 \mathrm{rpm})$ with no-load and loaded $(3 \mathrm{Nm})$ conditions. The motor speed and torque responses are given in Figure 13. and Figure 14., respectively.
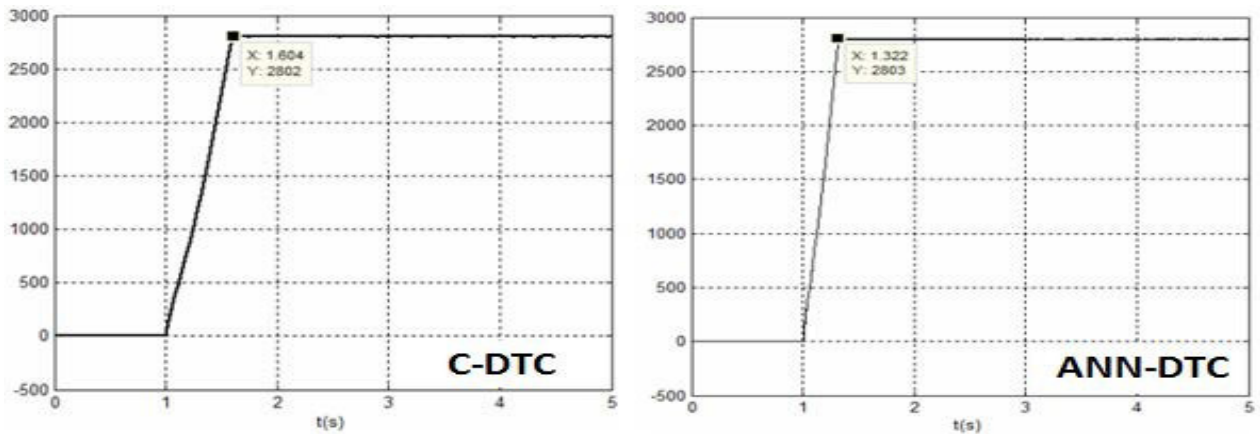

Figure 13. Motor speed responses at $2800 \mathrm{rpm}$ speed reference
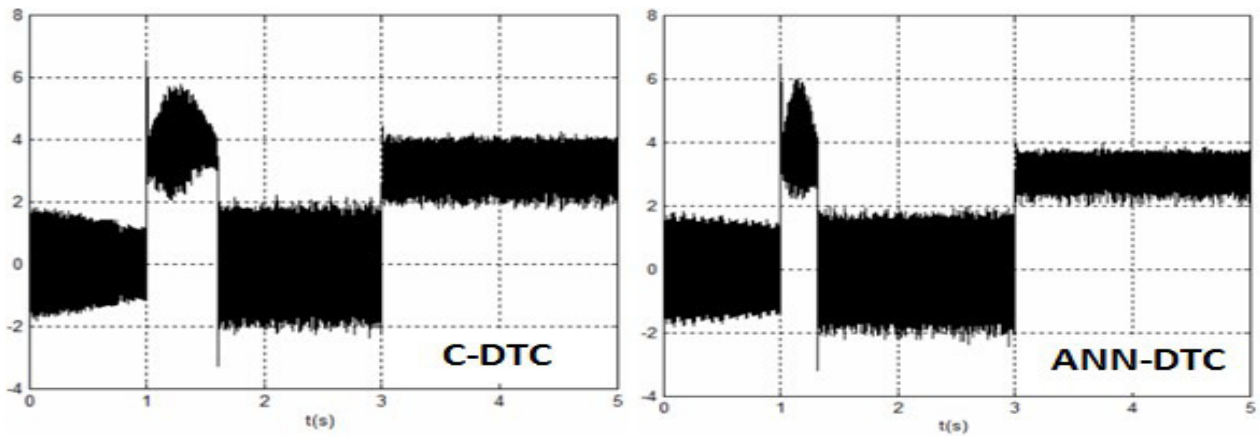

Figure 14. Motor torque responses at $2800 \mathrm{rpm}$ speed reference

The main difference for the proposed ANN-DTC method emerged in the third group of tests as can be seen clearly in Figure 13. and Figure 14. The speed response of the motor proved that ANN-DTC method had faster dynamic responses when compared C-DTC method. Time to reach the reference speed was about $\% 50$ faster in the proposed method. On the other hand, when the torque curves examined closely, it can be seen that torque ripples of the motor were reduced remarkably with the ANN-DTC method.

\section{CONCLUSIONS}

This paper presents a new artificial neural networks based approach to conventional direct torque control method for high performance control of induction motors. The aim of the paper is simplifying the complex mathematical process in conventional direct torque control method by usage of neural network models. For this aim, two independent neural models have been designed, trained and tested. The first neural model was designed for sectors determine process and the second one were designed for optimum switching select unit. Numerical simulations have been performed to investigate the effects of the proposed method on the overall system performances. Low speed and rated speed performances of the motor were simulated at zero 
loads and rated loads working conditions. Simulation results have been comparatively presented and they have been showed that proposed neural network based DTC method has better dynamic performance especially closer to rated speed values. The proposed method has faster acceleration time in transient state region and torque ripples were reduced with the proposed method in steady-state region. The practical works on the proposed method as a real time application are still going on and experimental results will be presented by researchers in the future works.

\section{APPENDIX}

Table 1. Simulation and motor parameters:

\begin{tabular}{|c|c|}
\hline Motor Power $(\mathrm{kW})$ & 4 \\
\hline Bus Voltage $(\mathrm{V})$ & 300 \\
\hline Phase resistance $(\mathrm{ohm})$ & 1,54 \\
\hline Flux Reference $(\mathrm{Wb})$ & 0,5 \\
\hline Flux Hysteresis Band & $\pm 0,05$ \\
\hline Torque Hysteresis Band & $\pm 0,5$ \\
\hline Sample time $(\mu \mathrm{s})$ & 10 \\
\hline
\end{tabular}

\section{REFERENCES}

[1] Blaschke, F.,(1972) "The Principle of Field Orientation Applied to The New Transvector ClosedLoop Control System for Rotating Field Machines”, Siemens-Rev., Vol. 39, 217-220.

[2] Takahashi Takahashi, I. \& Noguchi. T. (1986) "A new quick-response and high efficiency control strategy of an induction motor," IEEE Transactions on Industrial Applications, vol.I A- 22 ,No.5. , pp. $820-827$.

[3] Fatih Korkmaz. \& M. Faruk Çakır. \& Y1lmaz Korkmaz. \& Ismail Topaloglu, (2012) "Fuzzy Based Stator Flux Optimizer Design For Direct Torque Control" International Journal of Instrumentation and Control Systems (IJICS) Vol.2, No.4, pp 41-49.

[4] S.Kannan , S.Chinnaiya, S.U.Prabha Torque Ripple Minimization of Matrix Converter-Fed PMSM Drives Using Advanced Direct Torque Control International Journal of Soft Computing,Mathematics and Control (IJSCMC), Vol. 3, No. 4, November 2014pp. 51-68

[5] G. H. B. Foo and X. Zhang, "Constant Switching Frequency Based Direct Torque Control of Interior Permanent Magnet Synchronous Motors With Reduced Ripples and Fast Torque Dynamics," in IEEE Transactions on Power Electronics, vol. 31, no. 9, pp. 6485-6493, Sept. 2016.

[6] D.Premalatha, A.Sakthi Rubini "Direct Torque Control of Brushless DC Motor Using PI and Fuzzy Controller" International Journal of Science, Engineering and Technology Research (IJSETR) Volume 4, Issue 4, April 2015 pp.922-926

[7] Korkmaz, Fatih; Topaloğlu, İsmail; Mamur, Hayati; ,Fuzzy Logic Based Direct Torque Control of Induction Motor with Space Vector Modulation,"International Journal on Soft Computing,Artificial Intelligence and Applications",2,5/6,31-40,2015

[8] Bhim Singh, Pradeep Jain, A.P.Mittal, J.R.P.Gupta "Torque Ripples Minimization of DTC IPMSM Drive for the EV Propulsion System using a Neural Network" Journal of Power Electronics, Vol. 8, No. 1, January 2008 pp. 23-34

[9] F. Korkmaz "A New Approach to DTC Method For BLDC Motor Adjustable Speed Drives" The Fourth International Conference on Instrumentation and Control Systems(CICS-2016), vol. 6, no 5, pp-37-44, April 2016

[10] F. Korkmaz, I. Topaloglu, M.F. Cakir, R. Gurbuz, "Comparative performance evaluation of FOC and DTC controlled PMSM drives", Power Engineering, Energy and Electrical Drives (POWERENG), 2013 Fourth International Conference on , vol., no., pp.705-708, 13-17 May 2013.

[11] M. Masmoudi, B. E. Badsi and A. Masmoudi, "DTC of B4-Inverter-Fed BLDC Motor Drives With Reduced Torque Ripple During Sector-to-Sector Commutations," in IEEE Transactions on Power Electronics, vol. 29, no. 9, pp. 4855-4865, Sept. 2014.

[12] Vas, P., Sensorless Vector and Direct Torque Control, Cambridge University Press, 1998. 